\title{
Photocatalytic removal of cyclohexane on visible light-driven gallium oxide/carbon nitride composites prepared by impregnation method
}

\author{
Shu Chin Lee ${ }^{1}$, Wee Shern Chew ${ }^{2}$, Hendrik O. Lintang ${ }^{1}$, Leny Yuliati ${ }^{1 *}$ \\ ${ }^{1}$ Centre for Sustainable Nanomaterials, Ibnu Sina Institute for Scientific and Industrial Research, Universiti Teknologi Malaysia, 81310 UTM Johor Bahru, \\ Johor, Malaysia. \\ ${ }^{2}$ Department of Chemistry, Faculty of Science, Universiti Teknologi Malaysia, 81310 UTM, Johor Bahru, Johor, Malaysia. \\ *Corresponding Author: leny@ibnusina.utm.my
}

\section{Article history :}

Received 1 November 2015

Accepted 10 November 2015

\section{GRAPHICAL ABSTRACT}

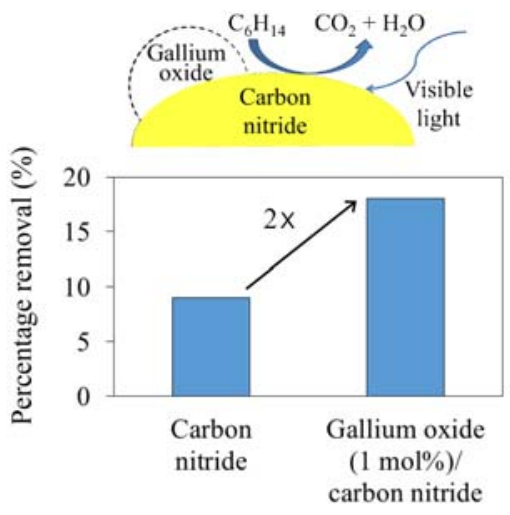

\section{ABSTRACT}

Carbon nitride is a material of interest for photocatalytic reactions due to its catalytic and visible light absorption properties. However, the photocatalytic activity is still low. Hence, modifications must be carried out to improve the photocatalytic activity of carbon nitride. In this work, a series of gallium oxide/carbon nitride composites with various gallium to carbon ratios $(\mathrm{Ga} / \mathrm{C}=1-50 \mathrm{~mol} \%)$ was prepared by impregnation method for removal of cyclohexane under visible light irradiation for the first time. The successful preparation of gallium oxide/carbon nitride composites was supported by several characterization techniques. X-ray diffraction (XRD) patterns and diffuse reflectance UV-visible (DR UV-vis) spectra revealed that the increased $\mathrm{Ga} / \mathrm{C}$ ratio resulted in the increased formation of $\mathrm{Ga}_{2} \mathrm{O}_{3}$. Furthermore, all the prepared composite samples also showed visible light absorption up to about 430 $\mathrm{nm}$. In the photocatalytic removal of cyclohexane under $6 \mathrm{~h}$ of visible light irradiation, sample with low loading of $1 \mathrm{~mol} \% \mathrm{Ga} / \mathrm{C}$ improved the photocatalytic activity of carbon nitride for two times. The high activity obtained on the gallium oxide $(1 \mathrm{~mol} \%)$ /carbon nitride composite clearly suggested the presence of synergic effect between small amount of gallium oxide and carbon nitride when they were combined. This study showed that a visible light-driven gallium oxide/carbon nitride composite could be prepared by impregnating a small amount of gallium oxide on carbon nitride and the composite is a potential photocatalyst for removal of cyclohexane under visible light irradiation.

Keywords: carbon nitride, visible light, gallium oxide, cyclohexane

(C) 2015 Penerbit UTM Press. All rights reserved http://dx.doi.org/10.11113/mjfas.v11n3.375

\section{INTRODUCTION}

Solar is the largest and free energy source available in the Earth. Sunlight comprises 5\% of UV, more than $40 \%$ of visible light region, while the rest is infrared. In order to fulfil the utilization of sunlight energy in the coming future, one of the potential applications could be visible lightdriven photocatalysis since there is large portion of visible light in the solar spectrum. Carbon nitride is a metal-free organic semiconductor that gains interest to be studied. It is able to absorb visible light with an absorption edge of 420$470 \mathrm{~nm}$ [1-7]. It possesses excellent catalytic properties and is chemically stable [1-5]. It has been also reported as a photocatalyst for reactions such as hydrogen evolution $[1,2,6]$ and removal of organic pollutants [1,3,4,7]. However, the photocatalytic activity of carbon nitride is still considered low and needed to be improved. Therefore, modifications on carbon nitride should be carried out.

On the other hand, gallium oxide is one wide band gap semiconductor that shows good activity for many reactions, such as photocatalytic reduction of carbon dioxide to produce methane [8,9] and syngas [10], photocatalytic non-oxidative coupling of methane [11], photocatalytic water splitting [12], and photocatalytic decomposition of volatile organic compounds (VOCs) such as benzene, ethylbenzene and toluene [13,14]. In the present study, carbon nitride was modified with gallium oxide through a simple impregnation method.

In order to test the activity of the prepared composites, photocatalytic oxidation of cyclohexane under visible light irradiation were investigated. Cyclohexane is one of VOCs that is released as an exhaust emission from many industrial processes [15], which can threaten human health and cause harm to the environment. Therefore, suitable methods should be developed to control the pollutants emitted from such processes. Unfortunately, only few studies were reported on the total oxidation of cyclohexane. Heterogeneous photocatalysis appears as an efficient approach for environmental application to decompose organic pollutants completely [1,3,4,7,13,14,16-19]. Since gallium oxide has been reported as a good photocatalyst for destruction of VOCs 
under UV light irradiation [13,14], series of gallium oxide/carbon nitride materials were applied for the photocatalytic removal of liquid phase cyclohexane under visible light irradiation for the first time in this study. This work showed that gallium oxide/carbon nitride composite with appropriate ratio of $\mathrm{Ga} / \mathrm{C}$ showed better removal of cyclohexane than the unmodified carbon nitride under visible light irradiation, hence, revealing that it is potential for visible light-driven reactions.

\section{EXPERIMENTS}

\subsection{Preparation of Photocatalysts}

For the preparation of carbon nitride, urea $(99.5 \%$, QRëC) was heated at a rate of $2.2 \mathrm{~K} \mathrm{~min}^{-1}$ to reach a temperature of $823 \mathrm{~K}$, and was tempered at this temperature for $4 \mathrm{~h}$.

For the preparation of gallium oxide, gallium(III) nitrate hydrate (99.999+\%, MV Laboratory, Inc.) was ground to powder, heated at a rate of $2.2 \mathrm{~K} \mathrm{~min}^{-1}$ to reach a temperature of $823 \mathrm{~K}$, and then, tempered at this temperature for $4 \mathrm{~h}$.

A series of gallium oxide (x mol\%)/carbon nitride composites $(\mathrm{x}=\mathrm{mol} \%$ ratio of gallium to carbon of $1 \%$, $5 \%, 10 \%, 20 \%$, and $50 \%$ ) were prepared by an impregnation method. Appropriate amount of gallium(III) nitrate hydrate (99.999+\%, MV Laboratory, Inc.) was dissolved in methanol (99.8\%, QRëC). While stirring, $1 \mathrm{~g}$ of the prepared carbon nitride was added onto the gallium nitrate solution. The mixture was continuously stirred and heated until the solvent was completely evaporated. The obtained powder was heated at a rate of $2.2 \mathrm{~K} \mathrm{~min}^{-1}$ to reach a temperature of $823 \mathrm{~K}$, and was tempered at this temperature for $4 \mathrm{~h}$.

\subsection{Characterizations of Photocatalysts}

X-ray diffraction (XRD) patterns of the prepared samples were recorded on a Bruker D8 Advance diffractometer at room temperature, using $\mathrm{Cu}-\mathrm{K} \alpha$ radiation $(\lambda=1.5406 \AA)$ at $40 \mathrm{kV}$ and $40 \mathrm{~mA}$. Absorption spectra of the samples were measured by using a Perkin-Elmer Lambda 900 diffuse reflectance (DR) UV-visible spectrophotometer, which barium sulphate was used as the reference in these experiments.

\subsection{Photocatalytic Testing}

Photocatalytic activities of the series of the gallium oxide/carbon nitride composites were evaluated for removal of cyclohexane under visible light irradiation. Cyclohexane solution (100 mM) was prepared by dissolving an appropriate amount of cyclohexane (99.99\%, Fischer Scientific) in acetonitrile solvent (99.9\%, Merck). The photocatalyst sample (50 mg) was dispersed in a jacketed beaker containing cyclohexane solution $(100 \mathrm{mM}$, $50 \mathrm{~mL}$ ), which the reactor system was equipped with a water cooling circulation. Prior to light irradiation, the solution was stirred in dark condition for $1 \mathrm{~h}$ to establish adsorption-desorption equilibrium. The system was then irradiated for $6 \mathrm{~h}$ at room temperature with a halogen fiber optic illuminator (MI-150, 150 Watt) equipped with an infrared cutoff filter. After separation of the catalyst by a membrane filter, the filtrates were then analyzed using GCFID (Shimadzu, GC-2014). The photocatalytic removal of cyclohexane was determined based on equation (1) below.

$\frac{C_{o}-C_{t}}{C_{o}} \times 100 \%$

where $C_{o}$ showed the initial concentration of cyclohexane after reaching adsorption-desorption equilibrium in dark condition, while $C_{t}$ showed the remained concentration of cyclohexane after the reaction.

\section{RESULTS AND DISCUSSION}

Figure 1 shows the diffraction patterns for bare carbon nitride, bare gallium oxide, and series of gallium oxide/carbon nitride composites. As can be seen in Figure 1 , carbon nitride has two main peaks in the XRD pattern, which are 12.95 and $27.65^{\circ}$, corresponded to in-plane ordering of tri-s-triazine units and typical (002) graphitic stacking of the conjugated aromatic units of carbon nitride, respectively. These diffraction patterns are in good agreement with the graphitic carbon nitride prepared from various precursors such as urea [3,7], cyanamide [2], and melamine precursor [4]. On the other hand, the prepared gallium oxide has three main peaks observed in the XRD pattern, which are $31.60,35.70$, and $64.15^{\circ}$. The diffraction pattern observed was close to the diffraction peaks of the $\gamma$ phase of $\mathrm{Ga}_{2} \mathrm{O}_{3}$, which was prepared in the presence of ethanol solvent and ammonia aqueous $[8,13,20]$. The broad lines of the diffraction pattern revealed low crystallinity of the gallium oxide sample. When a small amount of gallium oxide ( $1 \mathrm{~mol} \%$ of $\mathrm{Ga} / \mathrm{C}$ ratio) was present in the composite, only peaks of carbon nitride can be detected. However, with increasing the $\mathrm{Ga} / \mathrm{C}$ ratio to $5-20 \mathrm{~mol} \%$, diffraction peaks of gallium oxide can be observed in addition to the peaks of carbon nitride. When the $\mathrm{Ga} / \mathrm{C}$ ratio was high (50 mol\%), the diffraction peaks of gallium oxide became dominant and the peaks of carbon nitride could not be detected. These results clearly suggested that at low ratio of $\mathrm{Ga} / \mathrm{C}$, the produced composites mainly have carbon nitride phases, at moderate ratio of $\mathrm{Ga} / \mathrm{C}$, the produced composites have both carbon nitride and gallium oxide phases, while at high ratio of $\mathrm{Ga} / \mathrm{C}$, the produced composites mainly have gallium oxide phases. 


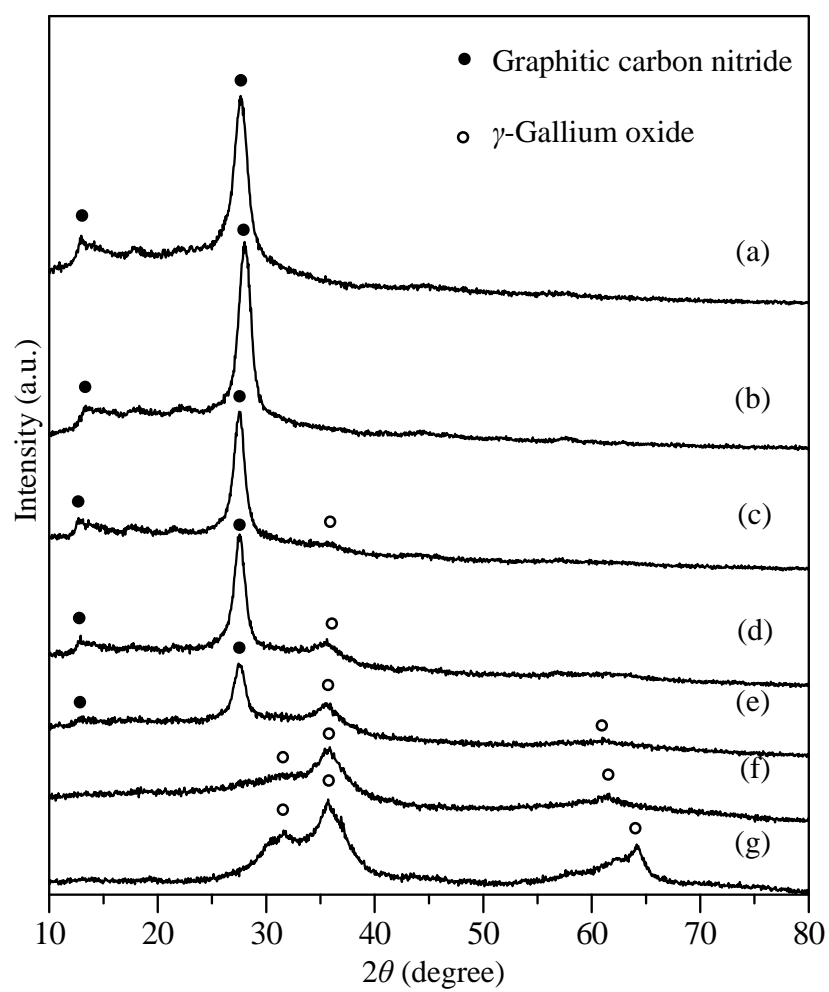

Fig. 1 XRD patterns of (a) carbon nitride, (b) gallium oxide (1 mol\%)/carbon nitride, (c) gallium oxide (5 mol\%)/carbon nitride, (d) gallium oxide (10 mol\%)/carbon nitride, (e) gallium oxide (20 mol\%)/carbon nitride, (f) gallium oxide (50 mol\%)/carbon nitride, and (g) gallium oxide

The optical absorption properties of the prepared samples are shown as DR UV-visible spectra in Figure 2. Carbon nitride showed visible light absorption up to about $430 \mathrm{~nm}$ that gave yellow colour as the characteristic of carbon nitride. The absorption edge of the prepared carbon nitride was close to the values reported in other literatures [1-5,7], in which slight variation of the absorption edge was influenced by the preparation method such as precursors and condensation temperature used that may lead to different local structure, packing, and defects formed during the preparation process. On the other hand, gallium oxide showed light absorption up to around $285 \mathrm{~nm}$, indicating that the gallium oxide can only absorb UV light. The absorption edge of the prepared gallium oxide was close to the reported $\gamma$-gallium oxide [8]. It is worthy noted that all of the gallium oxide/carbon nitride composites are able to absorb visible light up to about $430 \mathrm{~nm}$, close to that of the carbon nitride. As $\mathrm{Ga} / \mathrm{C}$ ratio increased, the absorption edge was shifted to lower wavelength, closer to the properties of gallium oxide. The shifting was most clearly observed on the gallium oxide $(50 \mathrm{~mol} \%) /$ carbon nitride, in which its main absorption peak lied between those of gallium oxide and carbon nitride. These results are in good agreement with the results of the XRD patterns. From these two characterizations, it can be suggested that

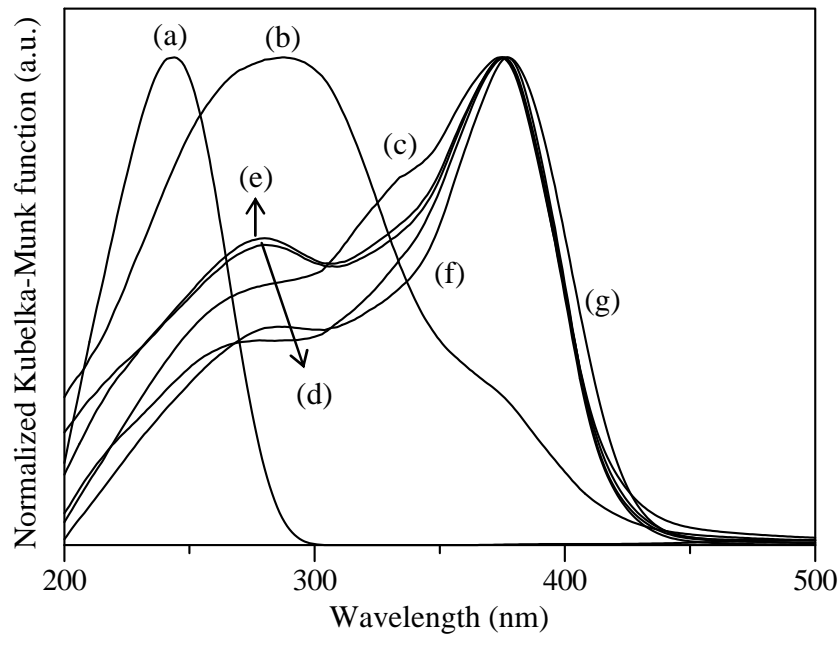

Fig. 2 DR UV-visible spectra of (a) gallium oxide, (b) gallium oxide $(50 \mathrm{~mol} \%) /$ carbon nitride, (c) gallium oxide (20 mol\%)/carbon nitride, (d) gallium oxide (10 mol\%)/carbon nitride, (e) gallium oxide (5 mol\%)/carbon nitride, (f) gallium oxide (1 mol\%)/carbon nitride, and (g) carbon nitride

gallium oxide/carbon nitride samples were prepared successfully by the impregnation method.

The photocatalytic activities of the gallium oxide/carbon nitride composites were evaluated for removal of cyclohexane under visible light irradiation for 6 $\mathrm{h}$ as shown in Figure 3. The activities of carbon nitride and gallium oxide (mol\% ratio of $\mathrm{Ga} / \mathrm{C}$ of 0 and 100 , respectively) were also shown for comparison. The optimum ratio for the removal of cyclohexane under visible light irradiation was $1 \mathrm{~mol} \%$, which increased the photocatalytic activity of the bare carbon nitride from 9 to $18 \%$. As the $\mathrm{Ga} / \mathrm{C}$ ratio increased, the gallium oxide/carbon nitride samples showed similar properties as well as photocatalytic activity to the bare gallium oxide. This result

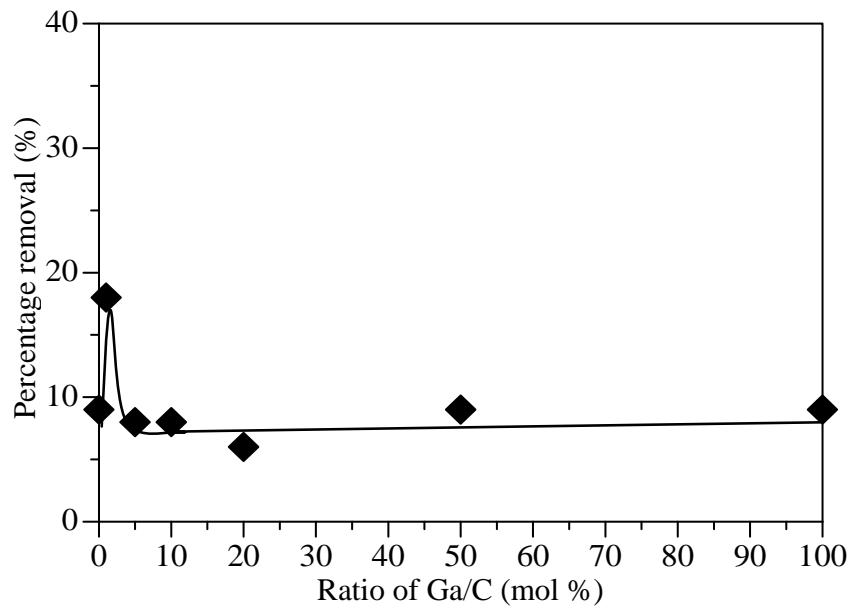

Fig. 3 Photocatalytic removal of cyclohexane on the series of gallium oxide/carbon nitride photocatalysts under visible light irradiation for $6 \mathrm{~h}$ 
suggested that there was a synergic effect between gallium oxide and carbon nitride when the ratio of $\mathrm{Ga} / \mathrm{C}$ was low. Analysis from GC-FID showed that other than the decrease in concentration of cyclohexane, the formation of cyclohexanol and cyclohexanone products was observed on the carbon nitride sample, but none of the intermediate product was observed on the gallium oxide/carbon nitride composites. The results suggested that in the presence of the composite photocatalysts and visible light, cyclohexane would be most probably underwent total oxidation to produce carbon dioxide and water. The results also showed that the composite photocatalysts can successfully decompose cyclohexane to non-hazardous compounds.

Based on the results mentioned above, it can be suggested that both gallium oxide and carbon nitride in the composite photocatalyst were important for the reaction. When the photocatalyst is irradiated under visible light, the electron excitation process will mainly occur in carbon nitride. Electrons will be promoted from the valence band to the conduction band of carbon nitride, leaving holes in the valence band to oxidize cyclohexane. Electrons on the conduction band of carbon nitride will react with dissolved oxygen from the atmosphere to form superoxide radicals that will further decompose cyclohexane to produce carbon dioxide and water. In this case, gallium oxide might help in the adsorption of cyclohexane that is important for the reaction to occur.

\section{CONCLUSION}

Gallium oxide/carbon nitride composites were prepared successfully by the impregnation method. All of the composites showed visible light absorption and were active for the removal of cyclohexane under visible light irradiation. For the oxidation of cyclohexane conducted under $6 \mathrm{~h}$ visible light irradiation, the highest activity was obtained on the composite with $\mathrm{Ga} / \mathrm{C}$ ratio of $1 \mathrm{~mol} \%$ with percentage of cyclohexane oxidation was $18 \%$, which was two times higher than the activity of bare carbon nitride. The good photocatalytic activity of the gallium oxide (1 mol\%)/carbon nitride would be due to the presence of synergic effect that exists between small amount of gallium oxide and carbon nitride. This study clearly showed that by impregnating a small amount of gallium oxide on carbon nitride can lead to better photocatalytic activity. It is suggested that the composite is potential for photocatalytic oxidation of cyclohexane under visible light irradiation.

\section{ACKNOWLEDGEMENTS}

This work was financially supported by the Ministry of Higher Education (MOHE) and Universiti Teknologi Malaysia (UTM) via a Tier-1 Research University Grant (cost center code: Q.J130000.2509.06H66).

\section{REFERENCES}

[1] Y. Wang, X. Wang, M. Antonietti, Angew. Chem. Int. Ed. 51 (2012) 68.

[2] X. Wang, K. Maeda, A. Thomas, K. Takanabe, G. Xin, J. M. Carlsson, K. Domen, M. Antonietti, Nat. Mater. 8 (2009) 76.

[3] J. Liu, T. Zhang, Z. Wang, G. Dawson, W. Chen, J. Mater. Chem. 21 (2011) 14398.

[4] S.C. Yan, Z.S. Li, Z.G. Zou, Langmuir 25 (2009) 10397.

[5] Y. Zhang, M. Antonietti, Chem. Asian J. 5 (2010) 1307.

[6] Y. Cui, J. Zhang, G. Zhang, J. Huang, P. Liu, M. Antonietti, X. Wang, J. Mater. Chem. 21 (2011) 13032.

[7] F. Dong, L. Wu, Y. Sun, M. Fu, Z. Wu, and S.C. Lee, J. Mater. Chem. 21 (2011) 15171.

[8] K. Teramura, H. Tsuneoka, T. Shishido, T. Tanaka, Chem. Phys. Lett. 467 (2008) 191.

[9] H.-a. Park, J.H. Choi, K.M. Choi, D.K. Lee., J.K. Kang, J. Mater Chem. 22 (2012) 5304.

[10] L. Yuliati, H. Itoh, H. Yoshida, Chem. Phys. Lett. 452 (2008) 178.

[11] L. Yuliati, T. Hattori, H. Itoh, H. Yoshida, J. Catal. 257 (2008) 396.

[12] Y. Sakata, Y. Matsuda, T. Yanagida, K. Hirata, H. Imamura, K. Teramura, Catal. Lett. 125 (2008) 22.

[13] Y. Hou, L. Wu, X. Wang, Z. Ding, Z. Li, X. Fu, J. Catal. 250 (2007) 12.

[14] Y. Hou, X. Wang, L. Wu, Z. Ding, X. Fu, Envi. Sci. Technol. 40 (2006) 5799.

[15] C. Hettige, K.R.R. Mahanama, D.P. Dissanayake, Chemosphere 43 (2001) 1079.

[16] K. Pirkanniemi, M. Sillanpää, Chemosphere 48 (2002) 1047.

[17] D. Chatterjee, S. Dasgupta, J. Photochem. Photobiol. C: Photochem. Rev. 6 (2005) 186.

[18] D.S. Bhatkhande, V.G. Pangarkar, A.A.C.M. Beenackers, J. Chem. Technol. Biotechnol. 77 (2002) 102.

[19] J. Peral, X. Domènech, D.F. Ollis, J. Chem. Technol. Biotechnol. 70 (1997) 117.

[20] B. Zheng, W. Hua, Y. Yue, Z. Gao, J. Catal. 232 (2005) 143. 